\title{
Corrigendum: Coronarin K and L: Two Novel Labdane Diterpenes From Roscoea purpurea: An Ayurvedic Crude Drug
}

\begin{abstract}
Venugopal Singamaneni ${ }^{1}$, Bashir Lone ${ }^{1,2}$, Jasvinder Singh ${ }^{2,3}$, Pankaj Kumar ${ }^{2,4}$, Sumeet Gairola ${ }^{2,4}$, Shashank Singh ${ }^{2,3}$ and Prasoon Gupta ${ }^{1,2 *}$

${ }^{1}$ Natural Products and Medicinal Chemistry Division, Indian Institute of Integrative Medicine, Jammu, India, ${ }^{2}$ Academy of Scientific \& Innovative Research (AcSIR), Ghaziabad, India, ${ }^{3}$ Cancer Pharmacology Division, Indian Institute of Integrative Medicine, Jammu, India, ${ }^{4}$ Plant Science Division, Indian Institute of Integrative Medicine, Jammu, India
\end{abstract}

Keywords: Roscoea purpurea, Astavarga, Zingiberaceae, labdane diterpenes, cytotoxic, coronarin K, coronarin L

\section{OPEN ACCESS}

Approved by:

Frontiers Editorial Office, Frontiers Media SA, Switzerland

*Correspondence: Prasoon Gupta guptap@iiim.ac.in

Specialty section: This article was submitted to

Organic Chemistry, a section of the journal

Frontiers in Chemistry

Received: 20 October 2021 Accepted: 20 October 2021 Published: 23 November 2021

Citation:

Singamaneni V, Lone B, Singh J, Kumar $P$, Gairola $S$, Singh $S$ and

Gupta $P$ (2021) Corrigendum:

Coronarin $K$ and $L$ : Two Novel Labdane Diterpenes From Roscoea purpurea: An Ayurvedic Crude Drug.

Front. Chem. 9:798461.

doi: 10.3389/fchem.2021.798461

\section{Corrigendum on}

Coronarin K and L: Two Novel Labdane Diterpenes From Roscoea purpurea: An Ayurvedic Crude Drug

by Singamaneni V., Lone B., Singh J., Kumar P., Gairola S., Singh S. and Gupta P. (2021). Front. Chem. 9:642,073. doi: 10.3389/fchem.2021.642073

In the original article, there was an error in affiliation 1. Instead of "Natural Product and Medicinal Chemistry Division, Indian Institute of Integrative Medicine, Jammu, India" it should be "Natural Products and Medicinal Chemistry Division, Indian Institute of Integrative Medicine, Jammu, India".

In the original article, there was an error in affiliation 2. Instead of "Academy of Scientific \& Innovative Research (AcSIR), Council of Scientific and Industrial Research, New Delhi, India," it should be "Academy of Scientific \& Innovative Research (AcSIR), Ghaziabad, India."

The authors apologize for this error and state that this does not change the scientific conclusions of the article in any way. The original article has been updated.

Publisher's Note: All claims expressed in this article are solely those of the authors and do not necessarily represent those of their affiliated organizations, or those of the publisher, the editors and the reviewers. Any product that may be evaluated in this article, or claim that may be made by its manufacturer, is not guaranteed or endorsed by the publisher.

Copyright $(2021$ Singamaneni, Lone, Singh, Kumar, Gairola, Singh and Gupta. This is an open-access article distributed under the terms of the Creative Commons Attribution License (CC BY). The use, distribution or reproduction in other forums is permitted, provided the original author $(s)$ and the copyright owner $(s)$ are credited and that the original publication in this journal is cited, in accordance with accepted academic practice. No use, distribution or reproduction is permitted which does not comply with these terms. 